\title{
Pastores del Sur Andino. Percepción y representación del ambiente*
}

\author{
Marcela Romo Marty**
}

\section{RESUMEN}

La presente investigación, realizada en la localidad de Ollagüe (II Región), tiene como objetivo describir la forma en que los pastores que allí habitan perciben su medio ambiente. Por medio de un estudio de casos en el que se combinan los métodos tradicionales de la antropología (observación participante y entrevista en profundidad), y técnicas específicas para el estudio de la percepción, se intenta una aproximación a este fenómeno, a través del análisis de los elementos de su etnogeografía, etnozoología y etnobotánica. Esta percepción es el resultado de proceso intelectual y filosófico milenario, que lleva a cada cultura a construir su propio modelo de la naturaleza, mediante el cual la estructura organiza y valora lo que en el plano de la acción orienta las formas de apropiación y utilización del entorno. En cuanto a los resultados, cabe destacar el conocimiento pormenorizado y exhaustivo de los componentes de su medio que poseen estos pastores andinos. Conocimiento que va unido a una percepción que puede ser calificada como "ecológica", ya que todos los elementos de su medio son respetados porque "están vivos" (montañas, ríos, plantas, animales), y en una permanente y natural interacción, integrando al hombre como uno más de ellos.
* $\quad$ Proyecto FONDECYT N 1970908.

$* *$

E-Mail: mromo@uec.inta.uchile.cl

\begin{abstract}
This investigation accomplished at the Ollagüe locality (II Región), has as objective to describe the way by which shepherds that there inhabit perceive their environment. Through a study of cases in which combine the traditional methods of the anthropology (participating observation and interview), and specific techniques for the perception study, is attempted an approximation to this phenomenon, through analysis of the elements of their ethnogeography, ethnozoology and ethnobotany. This perception is the result of a intellectual and philosophical millenary process, that carries to each culture to build his own natural model through which structure, organizes and values what in the plan of the action guides forms of appropriation and utilization of the environment. Concerning the results fits to emphasize the exhaustive and itemized knowledge of the components of mean that has these Andean shepherds. Knowledge that is going united to a perception that it can be qualified of "ecological", all the elements of their environment are respected since are live (mountains, rivers, plants, animals), and in a permanent and natural interaction, integrating to the human beings as one more of them.
\end{abstract}

\section{Introducción}

Las distintas sociedades humanas han ocupado y modificado los ecosistemas naturales para satisfacer sus necesidades. Más explícitamente, dentro de un proceso cultural observaron, experimentaron y acumularon conocimientos para utilizar los recursos de la naturaleza. Este enorme cúmulo de saber acerca del medio natural, que forma parte 
de un proceso intelectual y filosófico milenario, ha llevado a cada cultura a construir su propio modelo de la naturaleza, mediante el cual percibe y representa su entorno. La antropología debe jugar papel fundamental en el entendimiento integral de la participación de los seres humanos en los ecosistemas naturales, ya que por la complejidad del problema de la percepción del medio ambiente y los factores ecológicos, históricos y por sobre todo culturales que en ella inciden, se requiere de un esfuerzo especial para comprender la forma en que perciben su medio los distintos grupos sociales existentes en nuestra compleja sociedad contemporánea.

La zona norte de nuestro país posee singulares características climáticas y ecológicas, que condicionan una particular relación hombre-naturaleza marcada por el complejo y delicado manejo de los recursos naturales que allí existen. El objetivo de la investigación fue conocer la percepción que tiene un grupo de pastores andinos de su entorno (Romo 1998). A través de un estudio de caso, se intenta una aproximación a este fenómeno por medio del análisis de los elementos de su etnogeografía, etnozoología y etnobotánica. Se escogió como grupo de estudio a los pastores de la zona de Ollagüe, en el extremo noreste de la Región de Antofagasta, entre los $68^{\circ} 45^{\prime}$ y $68^{\circ}$ longitud oeste, y los $20^{\circ} 45^{\prime}$ y $22^{\circ}$ de latitud sur. Las unidades domésticas escogidas para el estudio de casos se encuentran ubicadas en los sectores de Amincha, Puquios y Chela (ver Figura 1).

\section{Percepción y representación}

La antropología siempre ha considerado la forma en que los seres humanos se relacionan con su ambiente. El mismo concepto de cultura, que ocupa el centro de la elaboración antropológica, se construyó alrededor de la necesidad de sistematizar la manera en que las diversas sociedades explican la realidad y como parte de ésta, la naturaleza. Esta investigación se refiere fundamentalmente a la relación entre tres elementos: el individuo, la cultura y el entorno, existiendo dos énfasis en los desarrollos teóricos con respecto a la relación entre dichos elementos. Por una parte, se plantea que es el medio ambiente el que, mediante sus constricciones, influye al individuo en el modelo que realiza de su entorno. La postura contraria privilegia, por otra parte, el aspecto ideacional en donde es la cultura la que modela esta construcción del entorno. Ambas perspectivas tienen valor y potencia explicativa, pero la situación es más compleja.

La aprehensión del entorno se ha investigado utilizando dos conceptos íntimamente ligados que son percepción y representación. La percepción se define en un sentido general como conciencia humana del medio y entendimiento del entorno, incluyendo así tanto la percepción sensorial directa como la cognición, es decir, aquellos procesos que hacen inteligibles los estímulos sensoriales
"En términos simples, la percepción social se define como los efectos de factores so- ciales y culturales sobre la forma en que se estructura nuestra cognición del entor- no psíquico y social. La percepción no de- pende únicamente de los estímulos presen- tes y de las capacidades de los órganos sensoriales. Ella depende igualmente de las experiencias pasadas del individuo y de su comportamiento actual que está mediado por valores, necesidades, recuerdos, humor (espíritu), de circunstancias sociales y as- piraciones." (UNESCO, 1977: 1).

La percepción del medio ambiente no está regida por lo que es "verdadero", sino por lo que se cree que es verdadero; son estas creencias las que modelan el comportamiento. A lo largo de su desarrollo, el individuo adquiere una percepción de su entorno deformada y filtrada por la cultura que lo envuelve. Cada persona aprende a percibir en un proceso que comienza en la primera infancia y prosigue a lo largo de toda la vida... (Ibid)

En cuanto a la representación social, ha sido definida por Jodelet como:

“... una forma de conocimiento elaborada y socialmente compartida, constituida a partir de la experiencia, las informaciones, saberes, modelos de pensamiento recibidos y transmitidos por la tradición, la educación y la comunicación social. Su objetivo es práctico. La representación apunta al dominio del entorno, a la com- 
prensión de los hechos y las ideas que dominan el entorno. La representación social participa en la construcción de una realidad común a un conjunto social" (en Viveros, 1993: 241).

Como podemos observar, ambos conceptos están referidos a construcciones o modelos cultural y socialmente elaborados para aprehender la realidad, donde son fundamentales los procesos socialización, la experiencia y la práctica. Sin embargo, el concepto de percepción tiene un énfasis mayor en la construcción e interpretación del entorno que realiza el individuo (nivel psicológico); mientras que el concepto de representación se ha aplicado a los modelos elaborados por los grupos sociales (nivel sociológico). Son caras de una misma moneda, el ser humano es individuo y sociedad, el conjunto de percepciones individuales devienen en colectivas, y las representaciones sociales son apropiadas por los individuos transformándolas en propias. En adelante utilizaremos indistintamente ambos términos, entendiendo que son "momentos" de un mismo fenómeno individual y social.

Las representaciones tienen como finalidad última la búsqueda del sentido, ya que todas las funciones de pensamiento confluyen hacia la producción de sentido al organizar o reorganizar, a partir de las significaciones producidas, las relaciones de los hombres entre sí y con la naturaleza. (Godelier 1989). Estas representaciones se desarrollan al interior de procesos históricos de gran dinamismo; así, no podemos olvidar que estamos frente a personas que si bien socializadas e insertas en una cultura determinada, están expuestas a múltiples influencias de otros grupos, mediante la educación y los medios de comunicación. Cada ser humano recibe durante su endoculturación ciertos modelos que serán modificados, reinterpretados o cambiados, producto de la experiencia y de las nuevas informaciones, y esta nueva percepción será retransmitida al grupo social produciéndose el cambio en las representaciones.

Representaciones y percepciones, en tanto la interpretación de lo real, organizan las formas adoptadas por las distintas actividades humanas y la manera en que estas se efectúan. Las taxonomías de plantas, animales, de suelos, de fenómenos climáticos, los esquemas de acciones materiales y de conductas simbólicas, están destinados a representar, interpretar, organizar y legitimar las acciones del individuo (Ibid). El conocimiento, la conceptualización, ordenamiento y clasificación construyen un mundo de experiencias y ambientes, y es a través de las palabras y de la forma de referirse y nombrar esa experiencia que nos es posible acceder a ella. Bonfil resalta la importancia del nombrar:

“... nombrar es conocer, es crear, lo que tiene nombre tiene significado, o si se prefiere, lo que significa algo tiene necesariamente un nombre... El estudio a fondo de estos vocabularios... aportará información de singular importancia acerca de los diversos principios y códigos que el hombre ha empleado para clasificar y entender el mundo natural en el que se ubica y forma parte" (en Vásquez 1992: 184).

No obstante, clasificaciones y sistemas clasificatorios no son solamente herramientas de la cognición, sino que, además, cumplen una función práctica. La práctica implica siempre una operación cognoscitiva, en donde los sistemas de clasificación y taxonomías son los que organizan la percepción y estructuran la práctica. No hay que olvidar que estas estructuras fueron producidas por la práctica desde generaciones sucesivas, bajo las condiciones de existencia de un determinado tipo, y son a su vez adquiridas a través de la práctica y aplicadas a través de la misma (Bourdieu 1977). Así, la representación descansa sobre tres fenómenos: el conocer, el nombrar y el usar.

\section{Metodología y área de estudio}

Este estudio se inserta metodológicamente en la línea de las investigaciones en etnociencia, particularmente en la etnoecología, subdisciplina que analiza las representaciones humanas de la naturaleza y trata de descubrir la lógica de sus principios (Conklin 1968). La etnografía, en esta investigación a microescala, tuvo como finalidad proveer de una descripción más rigurosa, con el fin de comprender cómo los individuos perciben y representan su medio ambiente. Para la consecución de los objetivos de este estudio, la observa- 
ción participante fue la técnica más apropiada, ya que permitió la combinación de la observación directa y la entrevista no estructurada. La información se complementó con entrevistas en profundidad, y entrevistas semiestructuradas, y la aplicación algunos instrumentos especialmente diseñados acerca de los temas de interés particulares de la investigación (geografía, botánica y zoología). Estos instrumentos fueron inspirados por los trabajos de Flores Ochoa (1988, 1994), Grebe (1986), Castro M. y cols. (1982), Aldunate y cols. (1981), Pereira (1996), UNESCO (1977) y Whyte (1977). Consistieron en la confección de mapas, trabajo con cartas geográficas, fotografías, confección de un herbario, y la presentación de láminas con dibujos de aves y diseños de camélidos para su reconocimiento.

El área de estudio escogida fue la comuna de Ollagüe, con una superficie de $2.915 \mathrm{~km}^{2}$, se ubica en la provincia de El Loa, a $217 \mathrm{~km}$ al NE de la ciudad de Calama. El área pertenece a la Puna Salada, destacando los salares de Ascotán (246 $\left.\mathrm{km}^{2}\right)$, San Martín o Carcote $\left(108 \mathrm{~km}^{2}\right)$ y Ollagüe (31 $\mathrm{km}^{2}$ aproximadamente); encontrándonos hacia el oriente con la quebrada de Chela, que sobresale por ser la única que desemboca en el río Loa llevando agua durante todo el año (Quintanilla 1983, Gundermann y González 1993; Castro V. 1987).

Esta zona se ha caracterizado desde tiempos remotos por ser un corredor por el que han transitado las poblaciones de Atacama y la zona de Lípez en sus relaciones de intercambio, económicas y de parentesco. El aislamiento y la falta de recursos ha llevado a una forma de poblamiento eminentemente temporal, supeditada a la existencia de explotaciones mineras (azufre y boro) en el lugar. En este contexto, los pastores, si bien existen en escaso número, constituyen la población más estable dentro de la zona, y se han introducido estratégicamente en la economía del lugar, insertándose de múltiples formas, ya sea transportando el mineral en sus animales, como proveedores de llareta para los procesos mineros, suministrando productos alimenticios o artesanales a los campamentos, o simplemente como mano de obra (Serracino 1975; Núñez y Dillehay 1978; Núñez y Santoro 1988; Castro V. et al. 1984; Mena 1984,
Martínez J. L. 1988; Hidalgo, 1992; Gundermann y González 1993).

Actualmente existen en la zona 13 unidades domésticas dedicadas al pastoreo. ${ }^{1}$ Estos asentamientos, preferentemente unifamiliares, se encuentran dispersos en pequeñas quebradas y vegas de borde de salar, y dedicados al pastoreo de llamas y ovejas. Se practica la crianza de algunos animales como gallinas, conejos y cuyes; y una agricultura para el autoconsumo en pequeñas superficies cercanas a los cursos de agua y protegidas por muros perimetrales. La agricultura realizada en pequeña escala, cultivándose quínoa, papas, habas, lechugas, zanahorias y cebollas principalmente. En cuanto al mercado de productos, este es principalmente de ganado (llamas y ovejas) destinado a los requerimientos de carne de los grupos no ganaderos del lugar. Tradicionalmente los ingresos de esta producción agropecuaria se complementaban con otros obtenidos por el trabajo en la minería o en actividades o relacionadas con ésta; sin embargo, hoy día la minería está fuertemente deprimida, lo que lleva a algunos pastores a completar sus entradas con subsidios o pensiones, trabajando en la prestación de servicios para la municipalidad, más el aporte que reciben de parientes que han migrado. Las unidades domésticas están compuestas en su mayoría por familias con hijos adultos, y son resultado de la migración de sus padres o de ellos mismos, predominando la migración desde Bolivia, aunque existen migrantes del altiplano de Iquique.

El pastoreo de ganado camélido es la principal actividad económica de este grupo, ya sea para el autoconsumo, la venta de los animales o la comercialización de sus subproductos. El pastoreo en la zona ha sido caracterizado por Castro $\mathrm{M}$. (1999) de la siguiente manera: existen largos circuitos de pastoreo estacional que alcanzan por el norte el Volcán Miño (nacimiento del río Loa), y por el este los pastizales bolivianos, se complementan las vegas salinas y los escasos cursos de agua, con los campos abiertos de pajonales y

Distribuidas de la siguiente manera: 2 en Amincha (Chaco), 2 en Kosca, 1 en Quebrada del Inca, 2 en Puquios, 3 en Chela (familias emparentadas), 1 en Cebollar y 2 en Ollagüe (Romo 1998). 
tolares; sin embargo, son los pastos estacionales que crecen después de las lluvias estivales los principales responsables del sustento, en complementariedad con las vegas. Producto de los déficit de forraje durante la estación fría, los pastores deben recurrir a las vegas de las orillas de ríos convirtiéndose aquellas en "zona de reserva forrajera estratégica en períodos de sequía” (Ibid.).

Chela es el sector que posee la mayor cantidad de cabezas, lo que coincide con una mayor cobertura vegetacional y agua dulce en abundancia, características muy superiores al resto del área. La repercusión de las características vegetacionales en la ganadería influye también en la composición de los rebaños. El animal predominante en todos los sectores es la llama seguido por los corderos, y después, en un número mucho menor, burros, cabras y alpacas. En los últimos años se han sucedido periodos de escasas precipitaciones, lo que ha producido una merma considerable en el número de cabezas de ganado existentes en la zona, y ha implicado cambios en la composición de los rebaños prefiriéndose las llamas, animales mejor adaptados a la escasez de agua, por sobre el ganado ovino que es menos resistente.

\section{Percepción del paisaje}

Los pastores estudiados pertenecen a un grupo de influencias quechuas y aimaras con un fuerte componente español, y que se ha desarrollado en condiciones históricas muy particulares. Presentan características distintas a las de los aimaras de la primera región, y también de las poblaciones del sector atacameño, pudiéndose postular que esta es una zona de transición entre ambos sectores, a lo que se suman elementos quechua parlantes de introducción más reciente, provenientes de Bolivia. $^{2}$

Antes de exponer los resultados es necesario hacer una aclaración. Cuando en la exposición de

La población indígena local se ha organizado constituyéndose como una comunidad quechua de acuerdo a la Ley Indígena.

3 Categoría intermedia que relativiza la distinción "cerca del agua".

$4 \quad V e g a$ es un término polisémico que puede referirse tanto a una unidad de paisaje como a una forma de vegetación, o una especie en particular. los datos hacemos referencia a la cultura andina o percepción andina, nos estamos refiriendo a presencia de elementos culturales que son comunes a toda el área andina (especialmente en lo referido a creencias, relatos míticos, conocimientos y tecnologías) y no a la existencia propiamente tal de una cultura andina pura.

En cuanto a los resultados, cabe destacar el conocimiento pormenorizado y exhaustivo de los componentes de su medio, el que es constantemente actualizado en cuanto a la ubicación exacta, cantidad y calidad de ellos. Uno de los principales factores que orientan la percepción es la distinción realizada entre "el agua" y "el seco", en torno a éstas, suelen agruparse las otras distinciones. ${ }^{3}$ Otro elemento importante es la altitud con su distinción "arriba" y "abajo". En torno a estos dos ejes se agrupa toda una serie de distinciones que tiene que ver con la temperatura, la presencia o ausencia de determinados tipos de vegetación o animales, el tipo de recurso que puede extraerse del lugar (agua, barro, arena, rocas), las características del suelo (salinos, arcillosos, arenosos), y su relación con determinadas costumbres o creencias. El conjunto de distinciones sirven para definir los distintos conceptos que describen su entorno.

Dentro de los elementos definidos por el eje agua/ seco, tenemos los ojos de agua, lugares donde afloran las aguas subterráneas y pueden ser el nacimiento de algunos cursos de agua. Tienen algunas características mágicas o sagradas, ya que en ellos habita un ser llamado serena, que entrega canciones a los músicos en la época de carnavales. Los cerros dan origen a los ríos, nombre que designa a los cursos de agua superficiales sin importar su tamaño. Una unidad muy importante relacionada con "el agua" es la vega." "La vega es todo lo plano con agua, en partes no hay mucha agua, está verde, en partes amarilla." (com. pers., Amincha 1996). La quebrada es una categoría que puede ser "del agua" o "del seco" dependiendo de las características del curso.

\footnotetext{
"Una quebrada es como el Inca, como quebrada de Amincha. Hay quebradas secas a veces hay ríos que bajan una quebrada que sea harto piegroso eso se llama río de piedras... Ahí en partes hay ese río
} 
de piedra que le digo yo, y las vizcachas no salen sino que iuh! por las piedras andan (com. pers., Ollagüe, 1996).

Con respecto a los conceptos relacionados con "el seco", tenemos la pampa, aquellos sectores planos y secos, la que puede estar ubicada a diferentes alturas, o bien ser un salar. Los salares son terrenos planos arenosos (que pueden tener algunas tolas) con sal y agua debajo, la que aflora en ciertos lugares formando lagunas. En torno a estas lagunas crece alguna vegetación y viven aves (parinas, caitis y “queilluas" (quelluas) principalmente) y animales (vicuñas).

En el eje espacial arriba/abajo el opuesto de pampa son las lomas y cerros. Las lomas, también denominadas chutu o morro, son elevaciones del terreno menores que los cerros. Tanto a las lomas, la pampa y la parte más baja de los cerros son denominados campo, lugar de las actividades productivas de recolección, caza y pastoreo. Esta zona del seco se caracteriza por las tolas.

"Amincha, del cerro más abajo, ahí hay más montecitos tolas, rica-rica, lampaya. Tola puro monte, en el seco lampayas, ricarica, $k$ 'iro en partes grandes, en partes agachada no más..."(com. pers., Ollagüe, 1996).

Subiendo nos encontramos con que la vegetación cambia encontrándonos con el sector de pajas.

“Cordillera más arriba, llareta, queñoa puede haber, paja más arriba también hay porque es más helado" (com. pers., Chela 1996).

Con respecto los cerros, en general se los considera como seres poderosos y se los invoca durante las ceremonias tradicionales ofreciéndoseles sacrificios. En cuanto a su morfología se distinguen partes como el pie del cerro (pampa), sus laderas (faldeos o cuesta) y su cima (punta). También se hacen distinciones entre los cerros, están los simples cerros y aquellos que forman parte de la cordillera. La cordillera estaría formada por los cerros más altos, donde dominan el frío y la nieve.
"Cuando es alto es cerro bien puede ser como a mediado de cerro así significa cordillera, o bien puede ser como ahora Aucanquilcha más arriba está más a la cordillera, más helado más cordillera. No tan helado cerro" (com. pers., Chela 1996).

El panizo se encuentra en la cordillera y se caracteriza por el frío, la nieve, la puna y la ausencia de vida, a excepción de algunas plantas especiales.

\begin{abstract}
"Panizo como yendo así digamos pa' Amincha, más al faldeo es una pampa con piedrecilla chica, ese le llaman panizo, en partes hay pajitas chiquititas, tola de chachacoma chiquita, crecen chiquitas porque el panizo es duro, no sé que será. Como ser esta pampa subimos para arriba un poquito y allí ya se hace panizo, chijroso, piedra chica en partes piedra pómez, rosada. Es más alto que una pampa un poquito subir filo así pasar esta fila de tierra que está acá...." (com. pers., Ollagüe 1996).
\end{abstract}

Las formaciones rocosas y rocas se integran dentro del paisaje, y pueden ser lugares de profunda significación. Reciben el nombre de carcanal aquellos sectores rocosos y abruptos en los que el acceso al ser humano se dificulta, y son negativamente valorados, ya que son lugares por donde no es posible transitar, "mal paso".

“... Ahí dice carcanal, peñasco, ahí dice que vive el león. Carcanal no se puede pasar, no lo podrán seguir" (com. pers., Amincha 1996).

"Carcanal ese que no puede entrar mal paso. Es piegroso no se puede entrar de a una persona, ese le dicen. Piedras grandes en unas partes no se puede pasar" (com. pers., Chela 1996).

Mientras que a los terrenos rocosos menos abruptos se les denomina salle.

"Salle cerro con piedras chicas... Salle pura piedra no más, no hay tierra partes no más tierra más piedra" (com. pers., Ollagüe, 1996). 
"Salle aquí en ese lado hay en cordillerane, ese baja no más, estamos caminando baja, piedra no más piedras chicas, que lo bajan, bajan. Salle no tiene tolas, pura piedra no más. Piedra grande también" (com. pers., Chela 1996).

Como podemos observar, los conceptos con que se refieren al paisaje corresponden a zonas ecológicas, donde se integran elementos bióticos y abióticos. Este conocimiento va unido a una percepción que puede ser calificada de "ecológica", ya que todos los elementos de su medio están vivos (montañas, ríos, plantas, animales), y en una permanente y natural interacción, integrando al hombre como uno más de ellos. Es un mundo en que todos sus componentes están enlazados, no existiendo entes independientes de los demás, cada componente es más que un recurso natural, es un miembro vivo del universo, y por ende, sus relaciones con los otros elementos son más importantes que él aisladamente (Greslou 1990(b); Van Kessel 1996).

Como es sabido, el agua es un recurso fundamental tanto para la subsistencia humana como para la ganadería. La falta de precipitaciones es causante de serias pérdidas para los ganaderos, fenómeno que sucede con cierta periodicidad. A la sequía actual se le suma la actividad minera que está explotando los recursos hídricos de la zona. El daño que produce este hecho es claramente percibido por los pastores.

\begin{abstract}
"Sacan agua de la vega que está en la primera región para la mina Michincha se está agotando porque no llueve, no nieva, entonces el agua no reproduce. La vega se ha estado secando desde el momento en que empezaron a sacar agua en grande se está secando. Antes había allí vicuñitas..." (com. pers., Ollagüe 1996).
\end{abstract}

La falta de lluvias es atribuida por algunos lugareños a una ruptura en el diálogo con la naturale$\mathrm{za}$, al abandono de las prácticas rituales propiciatorias de lluvias. Por ejemplo, una pastora afirmaba con respecto a las ceremonias en que se traía agua de mar para simbolizar la continuidad del ciclo del agua.
"Antes hacían, no, una ceremonia que hacían el 25 de Diciembre, el 4 de Diciembre, 1 de Enero. Con incienso, se hincaban pedían. Ahora por qué se cambiaron. Antes creo que traían agua de mar ahora ya no" (com. pers., Amincha 1996).

\section{La clasificación de las plantas y animales}

En todo este proceso de percepción del entorno son importantes las taxonomías y, dentro de éstas, las denominaciones o nombres son básicos en la formulación de conceptos; sin embargo, la falta de un "nombre" específico no quiere decir que no se realice alguna forma de clasificación. Muchas veces los informantes recurrieron a la palabra clase para dar cuenta de esta situación; afirmaciones como "hay varias clases de..." o " es de otra clase..." nos demuestran que, pese a la carencia de una denominación específica, era percibida una diferencia que se describía por sus atributos.

Se recogieron 301 nombres vernáculos diferentes de plantas; de éstos, 88 tienen alguna referencia en la literatura etnobotánica del Norte Grande (Aldunate et al. 1981, Castro et al. 1982; Munizaga y Gunckel 1958; Serracino et al. 1974). La vegetación es objeto de exhaustivas clasificaciones. Para reconocer una planta específica y asignarle un nombre se realizan observaciones principalmente referidas a sus características físicas y hábitat en que vive. A partir de la información recolectada se reconstruyó una etnotaxonomía que aparece en la Figura 2, donde fueron encontrados los siguientes niveles: la primera distinción básica corresponde a su ubicación en el eje agua/seco, distinción que se aplica también a las especies animales, y pareciera ser la más importante y elemental para los informantes; en un segundo nivel, una clasificación por forma de crecimiento lima, vega, llaretilla, paja, tola; luego un nivel de distinción definido por un atributo morfológico (por ej. espina para las cactáceas y tolas espinosas); en un cuarto nivel están las familias plantas, especies que reciben el mismo nombre pero son diferenciadas entre sí (por ej. marancel hembra y macho, chachacoma hembra, macho y de burro); y finalmente la distinción de especie que corresponde al máximo nivel de singularidad. Cuando se pregunta al informante qué planta es la que se le muestra o si la conoce, se referirá a ella hacien- 
do alusión a uno o más de los niveles antes mencionados, puede decir simplemente que es del agua y no sabe cómo se llama, hasta denominarla más específicamente subiendo los niveles de complejidad hasta llegar a la especie.

Existen otros criterios que distinguen a ciertas plantas, y aunque no se logró determinar un sistema clasificatorio basado en ellos, podemos nombrar: características de palatabilidad y nutricionales de los forrajes; atribución de sexo masculino o femenino; la época del año en que se utilizan los forrajes; y la distinción de plantas frías y cálidas en el caso de las plantas medicinales.

Del total de plantas colectadas en el herbario los informantes asignaron alguna utilización al 95\% de ellas. Una planta puede tener más de una forma de utilización, por ejemplo puede ser forrajera, medicinal y combustible al mismo tiempo. Los usos encontrados fueron principalmente forrajeros $(72,84 \%)$ y medicinales $(49,38 \%)$, y en menor grado como combustibles $(14,81 \%)$, alimenticios $(27,16 \%)$, artesanía $(7,41 \%)$, ritual $(3,7 \%)$ y construcción $(2,47 \%)$.

El conocimiento de la fauna, como ya se mencionó, está íntimamente ligado a todos los niveles del paisaje, es otro integrante más del ambiente y se refieren a ella aludiendo a los lugares que habitan, de qué se alimentan y su utilidad práctica para el hombre. De un total de 168 vernáculos recogidos, correspondientes a 112 especies identificadas por ellos, 60 tiene alguna referencia en la literatura etnozoológica de la zona (Castro V. 1986, Grebe 1986). Hay que hacer notar que entre los animales no pudo reconstruirse un esquema clasificatorio de la misma forma que en el caso de las plantas, existiendo por supuesto distinciones que permiten identificar a las especies, aunque no de una manera tan sistemática como en el caso de las plantas. En ciertos casos no parece haber más niveles que los de especie y forma de vida (por ej. quirquincho-animal), mientras que en el caso de los animales domésticos las distinciones se intensifican en el nivel intraespecie (Ver Figura 3). Los animales son identificados por el conjunto de sus atributos, entre los que mencionaremos como los más relevantes: el hábitat o lugar en el que viven; la morfología o aspecto externo de los animales (forma, tamaño, colorido, ruidos y cantos que emite, la forma y localización de sus huellas o fecas, etc.); el comportamiento del animal (hábito diurno o nocturno, estacionales o permanentes, costumbres alimenticias); finalmente, también es importante la relación que tiene el animal con el hombre. En cuanto a un esbozo de esquema clasificatorio en un primer nivel está el equivalente a las clases zoológicas mencionadas con los siguientes nombres: los animales (mamíferos), aves, y los bichos (insectos y arácnidos pequeños). Aquí podemos mencionar la existencia de un grupo de animales asociados discursivamente (que son nombrados juntos), y que si bien no se les atribuyó una denominación específica, se caracterizan por ser dañinos y provocar temor, estos son los reptiles y anfibios junto a dos arácnidos (tarántula y alacrán). En un segundo nivel existen agrupaciones por analogía con ciertos animales prototipo, generalmente domésticos o animales silvestres que se destacan por su abundancia o importancia, así se forman grupos de animales que son "como conejo" (liebre y vizcacha), "como llama" guanaco y vicuña. En un tercer nivel más específico existen denominaciones colectivas para algunas familias de animales como patos, pajaritos, zorros, ratones, culebras, lagartos, mariposas. Por último, tenemos las distinciones al nivel de especie, encontrándonos con un predominio de nombres simples, es decir, de una palabra (ej. guaicho).

Los pastores distinguen un número de especies que son de su propiedad y que ellos cuidan, que denominan "sus animales", por los que demuestran gran respeto y cariño. También existe una categoría intermedia de animales silvestres que son susceptibles de domesticar (por ej., burro silvestre, quirquincho, suri, parina, distintas clases de pato, y jilguero). Entre los animales domésticos las diferenciaciones fundamentales son al nivel de especie, realizándose en algunos casos muy finas clasificaciones a nivel intraespecie. Para clasificarlos, se recurre a criterios similares a los utilizados para los animales silvestres. Se realizan distinciones referidas a la presencia de híbridos o razas, el sexo del animal, la edad, el color, la forma y distribución de las manchas si las tiene, y otras características como la personalidad del animal, lo que coincide con los trabajos de Flores Ochoa (1988). 
Una forma especial de clasificación de los seres vivos es la que corresponde a las plantas y animales de los gentiles. Estos antepasados míticos poseen una ligazón simbólica con lo natural y sintetiza la idea de fertilidad y abundancia agrícola (Martínez G. 1976).

“...Pa' donde hay harto es pa' Caspana no porque esas chacras que tenían los abuelos, los chullpas antes, se nota bien clarito cuando yo iba a Caspana, en el cerro en el faldeo que esos son cerritos chicos está bien clarito como está hechos los tabloncitos, unos cuadritos pa' sembrar, están perdiéndose las piedras están cayéndose, pero es una cosa dura, como sabían sembrar ahí..." (com. pers., Ollagüe 1996).

Cada planta cultivada o animal doméstico actual corresponde, según Cereceda (1990), a una especie de planta o animal, que apareciendo hoy como silvestre, inútil e incluso dañina para el hombre actual, sirvió de sustento o perteneció a los chullpas. Características de estos cultivos de los abuelos es que surgen en forma espontánea, y no pueden ser consumidos por las personas, o su calidad no es óptima para el consumo humano. Tenemos el caso de la papa y la quínoa silvestres.

"Eran muy ricos dicen ellos sembraban así como en esto [mesa] sembraban las papas. Por aquí en el Inca salen en las piedras duro, pero yo no he cavado, dicen que es duro pa' cavar esa papa de gentiles. $Y$ esa nos puede sacar porque está en medio de la roca, algunos cavan harto y sacaban pero dicen que no cuece iduras!" (...) "Igual que su quínoa también no coce, porque esa quínoa que ahora siempre sale, nosotros sacamos, haba o quínoa mismo pero sale, ajara se llama, hay de todos colores igual que la quínoa entonces finita no más, uno la hace pero no cuece. Es diferente a la quínoa de uno, es bien finita sus granos. La usan para remedio, también hacen harina tostada. Pero para hacer caldo para eso no cuece. Pero hay distintos colores también hay roja, blanca, negras. Crece así no más, mi abuela decía quínoa del gentil. Por eso sale sin que la siembren sale cuando llegamos, con la lluvia sale no más" (com. pers., Ollagüe 1996).

Es interesante lo señalado por la informante acerca de la quínoa silvestre que sería utilizada para realizar ofrendas a los antepasados, los cerros y la Pachamama $^{5}$.

"Los abuelos hacían harina tostada... se hace como quínoa keilchi para que coman los abuelos, cerros y Pachamama" (com. pers., Ollagüe 1996).

Estos dobles silvestres de cultivos y animales domésticos actuales estarían reunidos bajo el adjetivo $\boldsymbol{k}^{\prime}$ ita (Ibid), por lo que resaltamos la denominación kitaconejo entregado por un informante para la liebre y el vernáculo quitamishi (mishi significaría gato en quechua) entregado por Castro V. (1986) para el gato montés; ambas corresponden a especies silvestres, las que asocian con animales domésticos (conejo y gato). Estos $\boldsymbol{k}$ 'ita resultan perjudiciales porque destruyen los cultivos, en el primer caso, y atacan los animales domésti$\cos$, en el segundo. Podríamos inferir que corresponden a animales domésticos de los gentiles, aunque no fue señalado explícitamente por los informantes.

\section{La utilización y apropiación del entorno}

Todo este conocimiento del ambiente le permite al pastor en la práctica individualizar los elementos y recursos de que dispone, manteniendo un inventario pormenorizado de los recursos disponibles en cada momento para su subsistencia. La lógica del aprovechamiento de los recursos se manifiesta en un uso diversificado, integral y múltiple de estos, que se refleja en las siguientes características: la utilización de más de un ecosistema (tolar, pajonal, panizo y vegas), la utilización de varias especies por ecosistema, localización preferente de las unidades de producción en áreas de ecotono (áreas de contacto de dos o más

Esto coincide con lo señalado por Cereceda: "la aara o ayara, una quínoa silvestre de color negro, es considerada el alimento principal de los chullpas, que preparaban con ella p'siqe (guiso tradicional de quínoa cocida)" (1990: 76-77). 
ecosistemas naturales, en este caso, orillas de vegas o salares); la diversificación de las actividades de los miembros de unidades de producción (caza, recolección, pastoreo, comercio, artesanía) (Vásquez 1992). Por otra parte, la forma de vida de los pastores andinos y las particularidades de su medio los lleva a una peculiar relación de apropiación y utilización que caracterizaremos a través de las distintas actividades que realizan en este. El pastoreo es la actividad más importante de los pastores y aquella que los relaciona de manera más intensa con su medio ambiente. Otras actividades importantes que requieren de estos conocimientos son la recolección referida principalmente a combustible, plantas medicinales, alimenticias y la caza hoy.

En la actividad de pastoreo son utilizadas grandes extensiones de territorio donde pastan los animales que incluyen orillas de cursos de agua y salares donde existen vegales, como también el campo, unidad que incluye la pampa y el cerro cuando existe allí la vegetación suficiente. Por lo tanto, existen lugares con forraje en forma permanente a orillas de los cursos de agua y los tolares y pajonales, y los pastos estacionales que aparecen después de las lluvias estivales. Hay especies que son significativamente valoradas por sus cualidades nutritivas como la piyaya y el unquillo, y también existen cuatro consideradas tóxicas ya que enferman al ganado e incluso pueden causarle la muerte: la paja secuya, el garbanzo, el chujcho y la charina o llaretilla de la vega.

Los animales, especialmente las llamas, recorren grandes extensiones de terreno por lo que un pastor puede ocupar un área significativamente amplia de territorio. Si bien las vegas no tienen propiedad se llegan a establecer límites explícitos o tácitos entre los pastores con respecto al sector que les corresponde a cada uno, o la época del año en que serán utilizados. Los animales fijan ciertos circuitos y comen en los mismos lugares aunque sean dejados libres, por lo que sus dueños saben en qué sector buscarlos.

Con respecto a la modalidad de pastoreo se pudo observar que el caso particular de los grupos del área estudiada se escapa en cierta medida a los patrones del área andina más nuclear (Perú y Bolivia), se trata de pastores de llamas, en asenta- mientos aislados y distantes unos de otros, con unidades domésticas de tipo unifamiliar, y en un claro proceso de sedentarización y asalariamiento (Gundermann et al. 1993). La crianza de llamos, como actividad productiva, se asocia a tiempos pasados, cuando las condiciones para su crianza eran distintas debido a la mayor cantidad de pastos de lluvias y de mano de obra familiar, y cuando la demanda de estos animales como medio de transporte era alta. Esto requería de un patrón de vida semisedentario, como el que aún conservan los pastores con un alto número de llamas. De acuerdo con Castro M. (1999) las modalidades de pastoreo en la zona serían:

a) Trasladar el ganado de acuerdo a los ciclos climáticos hacia zonas seleccionadas más arriba en verano y más abajo en invierno, donde los propios animales reproducen microcircuitos de pastoreo. La labor del pastor en estos casos es mantener un sistema de vigilancia o control periódico, concentrando la tropa cuando la dispersión traspasa los límites de la territorialidad definida. Es la situación observada en la zona de Amincha y Puquios y probablemente la más practicada. En general se trata de grupos de no más de 50 cabezas y pueden pasar incluso un par de meses sin que vayan a verlos. Sólo las crías de llama y las ovejas son encerradas en corrales y alimentadas con pasto de fardo en el invierno. En el caso de dos de los informantes con los que se trabajó, los animales son dejados con bastante libertad y circulan por los alrededores del asentamiento principal. Los animales de la unidad doméstica de Puquios recorren el área entre Puquios el salar de Alconcha y Cueva Negra, y el ganado de la unidad doméstica de Amincha recorrería los sectores de Ojo Amincha y Chaco hasta Cuchicha y las faldas de cerro Santa Rosa (Ver Figura 4).

b) Pastorear los animales en microcircuitos que implican una movilidad en espacios más extensos, acá el pastor guía los animales entre diferentes lugares de forrajeo. En este caso como el anterior, durante el día el animal queda libre para seleccionar los pastos de acuerdo a sus hábitos alimenticios. Este esquema corresponde a lo observado en Chela. Durante el otoño y la primavera los pastores permanecen en la estancia principal en la Quebrada del río Chela; dentro de la quebrada, las llamas son parcialmente dirigidas durante 
el pastoreo hacia el sector este u oeste alternativamente ("hacia arriba" de la vega o "hacia abajo" tomando como referencia la residencia). Durante el invierno, entre junio y agosto, se trasladan ocupando las vegas señaladas en el mapa, desde la Naciente del Río Loa hasta Patuno. En el verano, entre enero y marzo, los animales ocuparán los pastos de lluvia de los faldeos del cerro Chela, o serán trasladados hasta el salar de Carcote donde ocuparán las vegas del borde de salar (excepto Cuchicha) y del sector de Caichape (Figura 4).

c) En un caso extremo situamos aquellas familias que poseen un número reducido de animales, pudiendo alimentarlos con alfalfa y pastos de vegas cercanas al lugar de residencia.

Si bien ninguno de los informantes reconoció que en la actualidad pastoreen animales en Bolivia, esta fue una actividad habitual hasta hace un par de décadas, sobre todo en el sector norte del área de estudio, entre Puquios y Kosca y el salar de Laguani. Esta práctica se ha visto obstaculizada en los últimos años por las restricciones fitosanitarias, lo que ha terminado con parte de los circuitos de pastoreo tradicionales; sin embargo, se puede pensar que esta actividad aún persiste aunque en forma muy esporádica y reducida.

La cantidad de fuerza de trabajo con que se cuenta es determinante en la modalidad de pastoreo que se utilice. Mientras mayor sea número de personas con las que se cuente para el cuidado del ganado, mayor será la actividad de pastoreo. Aquellas familias que tienen menos personas para esta actividad optarán por una forma en que los animales estén más libres, y elegirán las llamas que requieren de menos cuidados.

No obstante, la forma de pastoreo no obedece a un modelo rígido. Muy por el contrario, posee una gran flexibilidad para adaptarse a los múltiples factores y variaciones del entorno como por ejemplo:

1. La composición del rebaño requiere de determinados manejos, las llamas no precisan de tanto pastoreo y generalmente se dejan solas, concentrándose los esfuerzos en el cuidado en los corderos, los que son vigilados constantemente. Las alpacas son más pastoreadas que las llamas, pero no tanto como los corderos. Los burros son dejados libres y se les va a ver de vez en cuando.
2. Los animales son guiados a los sectores en que hay mayor cantidad de pasto; sin embargo, muchas veces son trasladados a otros sectores para que no se agote el forraje de un área determinada y este pueda reproducirse.

3. La calidad de los pastos es determinante en la decisión de hacia dónde serán guiados los animales. Hay pastos que se prefieren porque se dice que poseen mejores cualidades nutritivas, y se evitarán los pastos tóxicos. Por ejemplo, en Chela, se prefiere llevar a los corderos hacia el sector de la desembocadura del río, por la mejor calidad de forraje.

4. La presencia del león o el zorro puede llevar también al traslado de los animales hacia lugares en que pueda protegerlos mejor de estos depredadores.

5. Los ciclos estacionales también son importantes en la movilidad de los pastores. En invierno se buscarán los lugares más protegidos y generalmente bajos donde haya menos nieve y frío y el forraje suficiente. En verano, en cambio, se trasladará el ganado donde se encuentren los mejores forrajes estacionales para que engorden. Aunque la modalidad de pastoreo sea del estilo libre, se suele pastorear más a los animales en el tiempo de verano ya que estos tienden a irse más lejos o a seguir otras tropas buscando los pastos estivales.

6. La llegada de otras tropas de animales de otros pastores puede motivar el traslado ya que se produciría competencia por los recursos, y los machos de los distintos grupos se agreden.

7. Las características del terreno también influyen en el lugar escogido para el pastoreo. Habrá terrenos que serán evitados por resultar riesgosos para los animales (terrenos muy pedregosos o pantanosos) y otros serán preferidos porque ofrecen una mejor visibilidad para cuidarlos.

Frente a situaciones críticas, como la de una sequía prolongada, se emprenden acciones tales como impedir la reproducción del rebaño, sacrificar algunos animales, y recurrir a suplementos alimenticios como la alfalfa. Una estrategia de incorporación reciente consiste en llevar los anima- 
les, especialmente las crías, al corral municipal, para que sean alimentadas con pasto. Para enfrentar las situaciones de escasez de forrajes, que se estaría volviendo crónica, existen algunos proyectos para plantar alfalfa para forraje. Esto ya se ha realizado en el sector de Quebrada del Inca y se espera extenderlo a otros sectores, para lo cual los ganaderos agrupados en la comunidad quechua se están organizando y ya han conseguido fondos de CONADI.

En cuanto al manejo que se hace de los recursos, los pastores tienen conciencia clara del daño que produce la sobreexplotación de estos. Frescos están en la memoria los años de la explotación de la llareta y la queñoa, que terminaron prácticamente con estas especies en el sector. Con el fin de preservar la flora, los pastores mueven a su ganado para que puedan renovarse los sectores explotados, y también existe aunque en escala muy reducida el riego de vegas. ${ }^{6}$ Asimismo se practica la quema de las vegas, aunque esto no se haría, según los informantes, con la finalidad de renovar el vegal, sino de despejar ciertas áreas que no tiene buena visibilidad para pastorear por el crecimiento de la huailla, o para ahuyentar a los depredadores.

Respecto a la localización de los asentamientos de pastores, esta puede observarse en la Figura 4. La ubicación está relacionada con la actividad de pastoreo existiendo asentamientos de carácter permanente o temporal. Todas las familias poseen una o dos casas que es el lugar de residencia de la familia durante la mayor parte del año; esta residencia de tipo permanente está ubicada en el lugar donde se realiza preponderantemente la actividad de pastoreo. Generalmente, está compuesta de varias habitaciones (2, 3 o más) construidas de barro con techo de paja. A su alrededor se sitúan algunos corrales para los animales y las pequeñas chacras donde cultivan hortalizas. En ciertos ca- sos, a esta residencia principal se suma una segunda en el poblado de Ollagüe, sobre todo cuando las necesidades de educación de los hijos así lo requieren. En el caso de los pastores que se trasladan a grandes distancias por períodos de tiempo variables, poseen residencias de tipo temporal consistentes en construcciones que pueden ser una o dos piezas o una choza. Destaca el caso de la familia de Chela, que por su gran movilidad posee asentamientos en múltiples lugares ${ }^{7}$, lo que no se da en los otros casos. Los asentamientos temporales pueden estar abandonados durante años, debido a la merma en las cabezas de ganado, o falta mano de obra para llevar a los animales a estos lugares. Sin embargo, los derechos de propiedad son reconocidos por el resto de los pastores, hasta que la persona fallece e incluso este derecho se traspasa a su familia.

La recolección y la caza son actividades a las que no se les atribuye mayor valor, pero realizan aportes importantes ya que constituyen una fuente rica de recursos, algunos indispensables y otros complementarios, dentro de la economía de los pastores. La recolección de plantas con fines medicinales es de gran importancia existiendo plantas específicas destinadas a la cura de enfermedades digestivas, respiratorias, sistema locomotor y traumatismos. Los órganos de las plantas más utilizados son la parte aérea (hojas y tallos), también se usan las raíces, frutos o semillas e inflorescencias. La forma de utilización más frecuente son las infusiones aunque también se recurre a diversas modalidades como parches, baños, inhalación, sahumerio, comerlas, etc.

La colecta de especies alimenticias es una actividad bastante abandonada en la actualidad, privilegiándose los alimentos adquiridos en la ciudad. Muchas veces la recolección de vegetales como alimento se considera una actividad de esparcimiento, practicada principalmente por niños, rales (Romo 1998). 
mientras se encuentran pastoreando. Entre las plantas comestibles destacaron las sichas ${ }^{8}$, y plantas como el berro, el chungulle y la achicoria o sike, el erso o bistro, y los frutos del piscayo y los del pingo pingo.

La recolección de combustible es otra actividad importante; generalmente, se intenta acopiar cantidad para varios días, en ocasiones con la ayuda de burros o vehículos para su transporte. Ciertas tolas son las plantas utilizadas comúnmente, aunque en este rubro destacan la llareta y la queñoa por considerarse los mejores combustibles. Debido a la depredación por parte de la actividad minera, en ciertos sectores como Amincha, los pastores deben realizar largas caminatas en búsqueda de la leña que necesitan.

Las plantas utilizadas para la actividad artesanal corresponden en su mayoría a plantas tintóreas (4 tolas), las cuales no se utilizan en la actualidad ya que han sido reemplazadas por las anilinas. En cuanto a materiales de construcción se nombró aquí a la paja brava para techar y la queñoa para hacer las vigas y postes de las casas; sin embargo, estos materiales también están siendo abandonados por otros "más modernos" como el zinc, o vigas de fierro, generalmente obtenidos de desechos de la actividad del ferrocarril o de los campamentos mineros.

En cuanto a las plantas rituales, destaca la tara coba o coba santiago, utilizada como incienso durante los floreos. Un informante señaló que cuando la cantidad de ésta escasea, se utiliza la tara macho mezclada con la anterior.

También existe la recolección de algunos productos animales en pequeña escala, centrada principalmente en la recolección de huevos de aves, especialmente patos. Además, se recolectan elementos con propiedades medicinales como el excremento de guaicho, y la pezuña de burro. También se colectan lagartos, para realizar compresas, con fines medicinales. Las plumas de ciertas aves tie-

"La sicha corresponde al rizoma tuberoso de la planta Ambrophyton subterraneum, que vive en las raíces de los arbustos del tolar" (Aldunate et al., 1981: 205). nen valor como las de parina utilizadas en rituales, y las de suri que son usadas en la confección de trajes de carnaval.

La caza está hoy muy restringida y se limita casi exclusivamente a la vizcacha para alimento y ocasionalmente algunas aves como la guallata, el suri, y las perdices. La actividad se ha visto afectada por las prohibiciones del Servicio Agrícola y Ganadero con respecto a la cacería de animales silvestres, por lo que los pastores temen sanciones por parte de esta institución. La medida gubernamental es repudiada principalmente cuando la existencia de ciertos animales depredadores causa graves pérdidas en la ganadería. También se registró la utilización de algunos subproductos de animales silvestres como la utilización de cueros de zorro en la confección de partes de prendas de vestir, la esquila de los cueros de vicuña para utilizar su lana, y la utilización medicinal de charqui de zorro y de culebra.

También se practica la captura de crías, polluelos o huevos para su crianza en cautiverio con la finalidad de utilizarlos para alimentación principalmente, aunque también como medio de transporte o simplemente como mascotas. Entre los animales con posibilidad de esta semidomesticación tenemos los suris, parinas, el jilguero y distintas clases de patos, el burro silvestre (que se utiliza para el transporte de carga teniendo más capacidad de resistencia que el burro doméstico) y el quirquincho (criado como mascota). No se detectó domesticación de camélidos silvestres, a excepción de una actividad observada, consistente en la crianza de una vicuña en el corral municipal, a la que los informantes no atribuyeron una finalidad específica; este animal habría sido encontrado en malas condiciones, por lo que un pastor lo habría llevado al lugar para su recuperación.

Un hecho importante que tiene que ver con el resultado de las representaciones que se realizan del medio ambiente, se relaciona con los fenómenos de apropiación de los recursos. En el caso de las comunidades estudiadas, más que propiedad, existen derechos sobre determinados sectores debido a su uso constante en el tiempo o a la presencia de una vivienda, heredándose también los derechos. Por otra parte, la propiedad del ganado es indivi- 
dual, aunque los rebaños generalmente se encuentran bajo el control familiar.

\section{Discusión}

La cultura andina ha sido abordada abundantemente desde variadas perspectivas como su modo de producción o su organización social, y en forma menos numerosa se han realizado trabajos acerca de la percepción del medio ambiente. Esto no sólo es un problema de los estudios andinos, ya que como Godelier afirma

\section{“... hacer un inventario de las realidades ideales incluidas en los distintos procesos materiales, que difieren según las culturas y según las épocas, es una tarea inmensa y enormemente dificil... pese a lo cual sigue siendo un terreno muy olvidado por las cien- cias humanas a pesar de las renovaciones aportadas por la etnociencia” (op. cit. 160).}

Como se ha señalado, las representaciones del ambiente son el producto del proceso de percepción, y no son un simple reflejo de "lo real", es una construcción que rebasa los límites del individuo, y proviene del medio social y cultural que lo rodea. Estas representaciones permiten a los pastores la interpretación del espacio en el que se insertan, comprender su orden y funcionamiento, interaccionar con él guiados por ciertas pautas y códigos de conducta, y finalmente legitiman su relación con la naturaleza.

Se ha observado, por parte de algunos investigadores, un intento, quizás, de legitimar las etnotaxonomías, con un excesivo énfasis en encontrar isomorfimos entre las taxonomías indígenas y científicas, como por ejemplo, en las investigaciones de Berlin y colaboradores (1960 y 1969), Royero (1989), Tournon (1991). En nuestro estudio, en el caso de las plantas, la taxonomía encontrada tiene bastante similitud con los niveles mencionados por Berlin en relación a forma de vida, género y especie. Sin embargo, en lo tocante a los animales, esta taxonomía difiere, encontrándose algunas posibles formas de vida y algunos pocos términos y agrupaciones por analogía, que corresponderían al nivel genérico o a algún nivel intermedio entre forma de vida y género. Es un hecho claro que las clasificaciones a partir de los atribu- tos morfológicos de plantas y animales, y del medio ambiente en general, se encuentran dentro de las más generalizadas e importantes. Sin embargo, las mismas investigaciones dan cuenta de taxonomías que no se rigen por este criterio, y que no siempre son estimadas valederas o son propuestas como clasificaciones con un nivel inferior. Por ejemplo, en trabajos realizados en distintas etnias, se han encontrado además del criterio de distinción morfológico, taxonomías que basan sus principios de distinción en la utilización que se hace de la especie (De la Torre 1985; Müller-Böker 1991; Tournon 1991; Castro V. 1986; Castro M. et al., 1982; Urday y Sotomayor, 1989; Greslou 1990a); ecológicas (Castro V., 1986; Aldunate et al. 1981; Castro M. et al. 1982; Gundermann 1984; Urday y Sotomayor 1989; Greslou 1990b); en principios ordenadores del universo (De la Torre 1985); en relaciones con divinidades o espíritus (Greslou 1990(a), Castro V. 1986; Grebe 1986); propiedades mágicas (Tournon 1991); tabúes (Royero, 1989), por nombrar algunos de los principios.

Con respecto a los principios de distinción que generan los sistemas de clasificación de animales y plantas, tenemos un sistema taxonómico en el que los atributos morfológicos son muy importantes para definir las especies, aunque muchas veces prima el hábitat de la especie y su ubicación en torno a los ejes antes mencionados, agua/ seco y arriba/abajo, a la hora de identificar muchas especies poco conspicuas. También está presente la distinción masculino/femenino en algunas especies de plantas, distinción de extensa utilización en el mundo andino. Es interesante el hallazgo de un principio de clasificación general que difiere del sistema científico, como son las plantas y animales "de los gentiles".

No hay que perder de vista que la existencia de distintos principios clasificatorios tiene que ver con la diversidad de prácticas y contextos en que son generados. Es posible que coexistan principios distintos dando origen a múltiples taxonomías, las que incluso pueden resultar contradictorias o incongruentes entre sí (Bourdieu 1977). Puede suceder que una persona clasifique una determinada especie en más de una forma dependiendo de contexto en que fue consultada. Por ejemplo, un informante se refirió a la planta guailla como una paja por su morfología, pero también la denomi- 
nó vega por el hábitat en que crece, y pasto por sus características forrajeras. Para Vander Ploeg las categorías de las etnoclasificaciones no son precisas y fijas sino que poseen "un estratégico margen de vaguedad", y esta imprecisión consciente en los conceptos permite un proceso activo y dinámico de interpretación de realidades diversas y cambiantes, a la vez que posibilita la comunicación (Greslou 1990b). Lo anterior se relaciona con otro fenómeno importante, que es el de la polisemia. No es raro que algunas palabras asuman múltiples significados, como por ejemplo: monte (planta, arbusto o planta medicinal), vega (paisaje, forma de crecimiento o especie específica), pasto (hierba, forraje), animal (mamífero, ganado), pampa (unidad de paisaje, cualquier sector plano, área lisa en un tejido). El significado en cada caso debe deducirse del contexto discursivo. También sucede el fenómeno contrario en que a un mismo elemento pueden aplicárseles múltiples nombres, como a la planta pingo pingo $=$ tume $=$ granadilla, $\mathrm{o}$ al animal zorrino=añatulla $=$ añasco, o al elemento geográfico loma=chutu chutu=morro que se asocia a las tradiciones culturales presentes en la zona y las distintas lenguas habladas en ella. Es interesante destacar que pese a que los informantes venían de tradiciones distintas, no se logró establecer diferencias significativas en cuanto a la terminología usada para denominar los elementos de la naturaleza, es más, un mismo informante podía manejar tanto el nombre quechua como aymara de un mismo elemento utilizándolos indistintamente.

En cuanto a los resultados obtenidos acerca del paisaje y el entorno físico, este se estructura teniendo como ejes dos atributos físicos: agua/seco y arriba/abajo. Dentro de estos dos ejes se sitúan una serie de entidades, personas, lugares (con distintas significaciones económicas o rituales), vegetación, animales, espíritus o divinidades en una constante interacción. Como señala Martínez (1977), los principios andinos arriba/acá/abajo, izquierda/derecha, agua/seco, son algunas de las tantas maneras en que el pensamiento andino categoriza una realidad intuida y aprehendida siempre como unidad de opuestos. Esta visión concuerda con lo encontrado en distintos trabajos realizados en grupos tradicionales de diversas culturas, donde la percepción ambiental se define por criterios físicos, ecológicos, religiosos y económicos (Bragg 1984; Ruiz y González-Bernaldes 1992; Greslou 1990b y 1990c; Aldunate et al. 1981).

Para los pastores, todos los componentes del paisaje están vivos interactuando permanentemente; todo el aparato ritual tiene como finalidad propiciar esta relación permitiéndole retirar los recursos que de él requiere, y a través de la reciprocidad ritual restablecer el equilibrio necesario (Flores Ochoa 1994). La percepción de las interacciones entre los diversos elementos alienta la preservación de la naturaleza y vida silvestre, produciendo lo que Grebe denomina "una tradición etnoecológica nativa". Esta etnoecología se basa en la existencia de "poderes" espirituales que guardan el entorno natural, poderes que se encuentra vivos y vigilantes (Grebe 1990).

La existencia de esta relación particular entre el grupo humano y la naturaleza queda plasmada en la percepción sensorial del grupo social, otorgándole una valoración afectiva. De esta percepción dependerán las valoraciones del medio ambiente (ya sean positivas, negativas, neutras o ambivalentes), las que son aprendidas al igual que lo cognitivo. Lo cognitivo y lo afectivo definen la evaluación que hace el individuo frente a una situación del entorno, determinando el tipo de afectividad hacia el lugar, su uso y manejo, la arquitectura y la artificialización del espacio (Pereira 1996; Bahamondes 1997). Se da el caso en que un objeto es valorado positiva y negativamente a la vez, como sucede con los lagartos y serpientes en que se les estima positivamente en cuanto a recurso medicinal, pero también se les considera como seres dañinos. Esto no es incongruente, ya que los contextos en que se producen las evaluaciones y las prácticas a las que están asociadas son disímiles (ritual y pastoreo), adjudicándosele diferentes cualidades de acuerdo a la situación, o al universo discursivo en que se interrogue (Bourdieu 1977). De la misma manera, la valoración de un ser puede ser ambigua como en el caso del cóndor en que se lo respeta por tener una significación "ser mallku", pero se le teme por ser un depredador de los rebaños. En general, la relación con la naturaleza está plasmada de esta ambivalencia con sentimientos de cariño, temor y respeto, producto de la percepción del entorno como un ser que da pero 
también quita, sobre todo si no se han establecido las relaciones de reciprocidad necesarias.

Cada sociedad llega a delimitar un territorio propio y una identidad construida en torno a una porción de la naturaleza y del espacio, que el grupo ha reivindicado como lugar donde sus miembros han encontrado permanentemente las condiciones y los medios materiales de su existencia. Pero este territorio es más que el espacio donde se asienta este grupo, en su internalización, unido a los procesos de significación, lleva finalmente a su transformación en un espacio vivencial amado y respetado (Pereira 1996). Entre los pueblos originarios de América, la naturaleza no es vista como enemiga, ni se asume que la realización plena del ser humano se alcance a medida que más se separe de la naturaleza. Se reconoce la condición del hombre como parte del orden cósmico y se aspira a una integración permanente, la misión de la humanidad es ajustarse armónicamente al cosmos, no domina ni pretende dominar, convive.

Sin embargo, la representación del entorno es un proceso dinámico que se ve afectado por los cambios históricos, ya que el pastor siente su territorio en función de sus problemas productivos y de sobrevivencia. La dimensión histórica de las representaciones nos permite comprender cómo la orientación andina tradicional hacia el entorno está cambiando hacia una de un tipo occidental. Esto se debe primeramente a que el sistema tecnoeconómico que les permitió a los pastores de llamos generar diversas formas de articulación a la economía andina y occidental, y que tuvo momentos de gran expansión, ha quedado hoy reducido al espacio familiar y comunal, y continúa reduciéndose (Castro M. 1999). Lo anterior es consecuencia de la pérdida de movilidad producto del endurecimiento en las normativas de tráfico en las fronteras geopolíticas, el término del uso de los llamos como medio masivo de transporte de carga, el debilitamiento creciente de los intercambios de sus productos, y el retiro de la actividad minera de la zona. Todos estos factores han provocado una creciente dificultad en la mantención de su forma de vida y modo de producción tradicional llevando al asalariamiento o subasalariamiento de muchas de las familias. Este fenómeno unido a las nuevas necesidades acarreadas por la integración del modelo occidental (por ej. la necesidad de una educación formal, o de mayor cantidad de bienes de consumo y tecnologías modernas) han llevado por un lado a una creciente sedentarización de las familias de pastores en torno al poblado de Ollagüe que puede satisfacer algunos de estos requerimientos, o simplemente a la migración hacia otros centros urbanos como Calama.

Puesto que los esquemas de percepción son generados en la práctica a través de generaciones y se reproducen en la misma práctica, el abandono, por ejemplo, del consumo alimenticio o medicinal de especies silvestres, o del uso de plantas tintóreas, y más aún el deterioro de las actividades de pastoreo, estarían produciendo cambios notables en los esquemas de percepción. Todos estos cambios han tenido como consecuencia una nueva percepción del entorno, sobre todo por parte de los más jóvenes, orientándose hacia el modelo occidental con una tendencia claramente extractiva. El medio ollagüino es considerado ahora como carente de los recursos necesarios, y la actividad pastoril demasiado sacrificada, dándosele una valoración negativa por oposición a la ciudad y la vida moderna.

El conocimiento tradicional muchas veces ha sido considerado como un falso conocimiento, un conocimiento reaccionario al cambio modernizador, o un conocimiento menos verdadero que el dominante (Menéndez 1988). Sin embargo, en los últimos años, ha surgido una postura de revaloración del saber popular, por parte de los autores postmodernos como Lyotard, resaltando su persistencia a pesar de la invasión totalizadora de la cultura occidental-moderna, ya que despliega sus propias estrategias de legitimación diferentes a la de la ciencia (Rabey 1990). La amenaza real que ha resultado de la aplicación de un modelo económico que atenta contra la sustentabilidad planetaria ha provocado la toma de conciencia sobre el deterioro ambiental, lo que ha otorgando a las minorías, entre ellas a las minorías étnicas, mejores posibilidades de resistir la expansión de los esquemas de representación del entorno medio ambiente basados en el modelo económico dominante. La revaloración de los saberes tradicionales podía ser un camino para la superación de la pobreza de estos grupos étnicos, a través del denominado el tránsito desde identidades territoriales 
fortalecidas por el aislamiento y la falta de oportunidades, a identidades territoriales fortalecidas por una elección consciente, ejercida en un marco de alternativas posibles (Sabatini 1997). Para que eso sea posible debe existir una voluntad política que entregue efectivamente a estos grupos los recursos y posibilidades reales para su desarrollo, y una mayor capacidad de control efectivo sobre lo que sucede en sus territorios. Los proyectos que afecten a las comunidades indígenas no sólo deben estar incorporados a un plan estratégico de desarrollo local ambientalmente sustentable que vele por los intereses locales, y respete los ecosistemas y la cultura de estos pueblos, sino que también debe incorporarlos en su planeamiento y diseño. Es necesaria la toma de conciencia de la sabiduría milenaria del saber de estos grupos, marginados socialmente en la actualidad, y fomentar el respeto por los etnoconocimientos y su conservación, como un patrimonio de los pueblos originarios de estas regiones que debe potenciarse para propender a su desarrollo y al bienestar de toda la humanidad.

Agradecimientos Un profundo reconocimiento a todos los ollagüinos que hicieron posible este estudio.

\section{BIBLIOGRAFIA}

\section{ALDUNATE, C., J. ARMESTO, V. CASTRO y C. VILLAGRAN 1981 Estudio etnobotánico en una comunidad precordillerana de Antofagasta: Toconce. Boletín Museo Nacional de Historia Natural (38) Santiago.}

BAHAMONDES, M. La construcción diferenciada del entor1997 no natural y la evaluación del impacto ambiental: los campesinos y los recursos naturales. Actas del Segundo Congreso Chileno de Antropología. Valdivia. Colegio de Antropólogos de Chile. Santiago.

BERLIN, B., D. BREDLOVE y P. RAVEN. Covert categories 1960 and Folk Taxonomies. American Anthropologist 70.

BERLIN, B., D. BREDLOVE y P. RAVEN. Taxonomies and 1969 biological classification. En: S. Tyler Ed. Cognitive Anthropology. Rinehart and Wiston. New York.

BOURDIEU, P. Outline of Theory of Practice.Cam1977 bridge University Press.

BRAGG, K. Los conceptos linguísticos de la divi1984 sión del espacio, tiempo y actividades en una comunidad pehuenche. Actas Jornada de Lengua y Literatura Mapuche. Universidad de la Frontera. Temuco.
CASTRO, M., C. VILLAGRAN y M. KALIN. Estudio etno1982 botánico en la cordillera y altiplano de los Andes del norte de Chile (18-19 $\mathrm{S})$. El Hombre y los Ecosistemas de Montaña 2. Proyecto MAB-6. Santiago.

CASTRO, M. Llameros de Puna Salada en los Andes 1999 del norte de Chile. En Y. Kobayashi y J.F. Ochoa (Eds.). Origen y Actualidad de los pastores altoandinos. En prensa.

CASTRO, V. An approach to the Andean ethnozoolo1986 gy: Toconce. Cultural Attitudes to Animals 2. Allen \& Unwin. Londres.

CASTRO, V. Provincia el Loa Chile. Informes I, II 1987 y III.Especialidad Estudios Antropológicos CONSECOL. Ms. in lit. Santiago.

CASTRO, V., C. ALDUNATE y J. BERENGUER. Orígenes 1984 altiplánicos de la Fase Toconce. Estudios Atacameños 7. Instituto de Investigaciones Arqueológicas y Museo R.P. Gustavo Le Paige s.j. Antofagasta.

CASTRO, V. y J. L. MARTINEZ. Poblaciones indígenas de 1996 Atacama. En: J. Hidalgo, Schiappacasse V., H. Niemeyer, C. Aldunate y P. Mege Eds. Etnografía. Sociedades indígenas contemporáneas y su ideología. Editorial Andrés Bello. Santiago. 
CERECEDA, V. A partir de los colores de un pájaro. 1990 Boletín del Museo Chileno de Arte Precolombino 4. Santiago.

CONKLIN, H. Comment on the etnographic study 1968 of cognitive systems. En: M. Fried Ed. Reading in Anthropology. Columbia University. EEUU. pp. 96-101.

DE LA TORRE, A. Experiencia y representación del mun1991 do natural en Cajamarca. Anthropológica 3. Departamento de Ciencias Sociales, Universidad Católica del Perú. Perú.

FLORES OCHOA, J. Clasificación y denominación de camé1988 lidos sudamericanos. En: J. Flores Ochoa Ed. Llamichos y paqocheros. Pastores de llamas y alpacas. CEAC, UNSAAC. Cuzco.

1994 Pastoreo andino contemporáneo. En J. Blassi Ed. Oro de los Andes. Las llamas, alpacas, vicuñas y guanacos de Sudamérica. Barcelona.

GODELIER, M. Lo ideal y lo material. Pensamiento, 1989 economías, sociedades. Editorial Taurus Humanidades. España.

GREBE, M.E. Etnozoología andina. Concepciones e 1986 interacciones del hombre andino con la fauna altiplánica. Scripta Ethnológica 10. Centro Argentino de Etnología Americana. Buenos Aires.

1990 Patrones supralinguísticos en la cognición y simbolismo andinos. En Actas I Simposio sobre Cognición, Lenguaje y Cultura. Chile. Universidad de Chile. Santiago.

GRESLOU, F. Visión y crianza campesina de los ani1990(a) males andinos. En: PRATEC- PAA PNUMA. Sociedad y naturaleza en los Andes. Tomo II. Lima.

1990(b) Visión y crianza campesina de los animales andinos. En: PRATEC-PAAPNUMA. Sociedad y naturaleza en los Andes. Tomo II. Lima.

1990(c) Visión y crianza campesina de los animales andinos. En: PRATEC-PAAPNUMA. Sociedad y naturaleza en los Andes. Tomo II. Lima.

GUNDERMANN, H. Ganadería aymara, ecología y forrajes: 1984 Evaluación regional de una actividad productiva andina. Revista Chungará 12. Universidad de Tarapacá. Arica.
GUNDERMANN H. y H. GONZALEZ. Estudio de diagnós1993 tico de la Comuna de Ollagüe. Taller de Estudios Andinos (TEA). Corporación Norte Grande. Arica.

HIDALGO, J. Mercado y etnicidad: Lecturas de la Re1992 visita de Atacama de 1683. Estudios Atacameños 10. Universidad Católica del Norte. Instituto de Investigaciones Arqueológicas y Museo R.P. Gustavo Le Paige s. j. Antofagasta.

MARTINEZ, G. El sistema de los uywiris en Isluga. En: 1976 G. Le Paige. Homenaje al R.P. Gustavo Le Paige. Universidad del Norte. Santiago.

MARTINEZ, J.L. Dispersión y movilidad en Atacama 1988 Colonial. En: O. Silva, E. Medina y E. Téllez Eds. Encuentro de Etnohistoriadores. Serie Nuevo Mundo, Cinco Siglos $N^{\circ}$ 1. Departamento de Historia. Facultad de Filosofía, Humanidades y Educación. Universidad de Chile. Santiago.

MARTINEZ, M.A. Percepción botánica de dos grupos étni1987 cos de la sierra norte de Puebla. América Indígena. 47 (2). Instituto Indigenista Interamericano. México.

MENA, F. Patrones de movilidad en el arcaico tar1984 dío: II Región. Estudios Atacameños 7. Universidad Católica del Norte. Instituto de Investigaciones Arqueológicas y Museo R.P. Gustavo Le Paige s. j. Antofagasta.

MENENDEZ, E. Medicina tradicional o medicina cientí1988 fica. Hacia una práctica unificada de los conjuntos sociales. Runa 17-18. Instituto de Antropología, Universidad de Buenos Aires. Buenos Aires.

MÜLLER-BÖKER, U. Knowledge and evaluation of the en1991 vironment in traditional societies of $\mathrm{Ne}$ pal. Mountain Research and Development 14 (3). International Mountain Society and United Nations University. EE.UU.

MUNIZAGA, C. y H. GUNCKEL. Notas Etnobotánicas del 1958 Pueblo atacameño de Socaire. Publicación del Centro de Estudios Antropológicos 5. Universidad de Chile. Santiago.

NUÑEZ, L. y T. DILLEHAY. Movilidad Giratoria, Armo1978 nía Social y Desarrollo en los Andes Meridionales. Patrones de tráfico e interacción económica. Facultad de Ciencias Sociales. Departamento de Arqueología. Universidad de Chile. Santiago. 
NUÑEZ, L y C. SANTORO. Cazadores de puna seca y salada 1988 del área centro sur Andina (Norte de Chile). Estudios Atacameños 9. Universidad Católica del Norte. Instituto de Investigaciones Arqueológicas y Museo R.P. Gustavo Le Paige s. j. Antofagasta.

PEREIRA, D. Gestión ambiental campesina del te1996 rritorio en comunidades de la Segunda Sección de la Provincia de Charcas, Departamento de Potosí, República de Bolivia. Tesis para optar al Grado de Magister en Asentamientos Humanos y Medio Ambiente. Pontificia Universidad Católica de Chile. Santiago.

QUINTANILLA, V. Geografía de Chile. Biogeografía To1983 mo III. Instituto Geográfico Militar.

RABEY, M. Sistemas de conocimiento popular en los Andes de noroeste argentino. Cuadernos 2. Facultad de Humanidades y Ciencias Sociales. Universidad Nacional de Jujuy. Jujuy.

ROMO, M. Percepción y representación del am1998 biente en un grupo de pastores andinos. Memoria para optar al Título de Antropólogo, Departamento de Antropología, Facultad de Ciencias Sociales. Universidad de Chile. Santiago.

ROYERO, R. Contribución al etnoconocimiento de la 1989 etnoictiología Piaroa (Dearuwa). Antropológica 72. Instituto Caribe de Sociología y Antropología. Caracas.

RUIZ J.P. y GONZALEZ-BERNALDEZ. Landscape percep1982-1983 tion by its traditional users: the ideal landscape of Madrid livestock raisers. Landscape Planning 9. Elsevier Publishers. Amsterdam.

SABATINI, F. Conflictos ambientales en América La1997 tina. ¿Distribución de externalidades o definición de derechos de propiedad?. En F. Sabatini y C. Sepúlveda (Eds.). Conflictos Ambientales. Entre la Globalización y la Sociedad Civil. Publicaciones CIPMA. Santiago, Chile.

SERRACINO, G. Los movimientos de los cazadores y 1975 recolectores en la cordillera de los Andes, entre la latitud $21^{\circ}$ y $26^{\circ}$ y longitud $67^{\circ} 00^{\prime}$ y $70^{\circ} 22^{\prime}$. Estudios Atacameños 3. Universidad Católica del Norte. Instituto de Investigaciones Arqueológicas y Museo R.P. Gustavo Le Paige s. j. Antofagasta.

SERRACINO, G., R. STEHBERG y G. LIBERMAN. Infor1974 me etnobotánico de Guatín (San Pedro de Atacama). Antropología Nueva Epoca 1. Departamento de Ciencias Antropológicas y Arqueológicas. Universidad de Chile. Santiago.

TOURNON, J. Clasificación de los vegetales en los 1991 shipiboconibo. Anthropológica 9. Departamento de Ciencias Sociales, Universidad Católica del Perú. Perú.

UNESCO. Methodes et interpretation de la re1977 cherche sur la perception de l'environement. MAB. Canadá.

URDAY, F. y SOTOMAYOR M. Uso de la tierra, clasifica1989 ción campesina y pastoreo en comunidades aymaras. Proyecto Alpacas IIAA. Puno.

VAN KESSEL, J. La cosmovisión aymara. En: J. Hidalgo, 1996 V. Schiappacasse, H Niemeyer, C. Aldunate y P. Mege Eds. Etnografía. Sociedades indígenas contemporáneas y su ideología. Editorial Andrés Bello. Santiago.

VASQUEZ, M.A. Etnoecología para un México profundo. 1992 América Indígena 52 (1-2). Instituto Indigenista Interamericano. México.

VILLAGRAN, C. y CASTRO V. Etnobotánica y manejo ga1999 nadero de las vegas, bofedales y quebradas del Loa Superior, Andes de Antofagasta, Segunda Región, Chile. Chungara. En prensa.

VIVEROS, M. La noción de representación social y su 1993 utilización en los estudios sobre salud y enfermedad. Revista Colombiana de Antropología 30. Instituto Colombiano de Antropología. Bogotá.

WHYTE, A. Guidelines for field studies in environ1977 mental perception. En: MAB Technical notes 5 . UNESCO. Francia. 


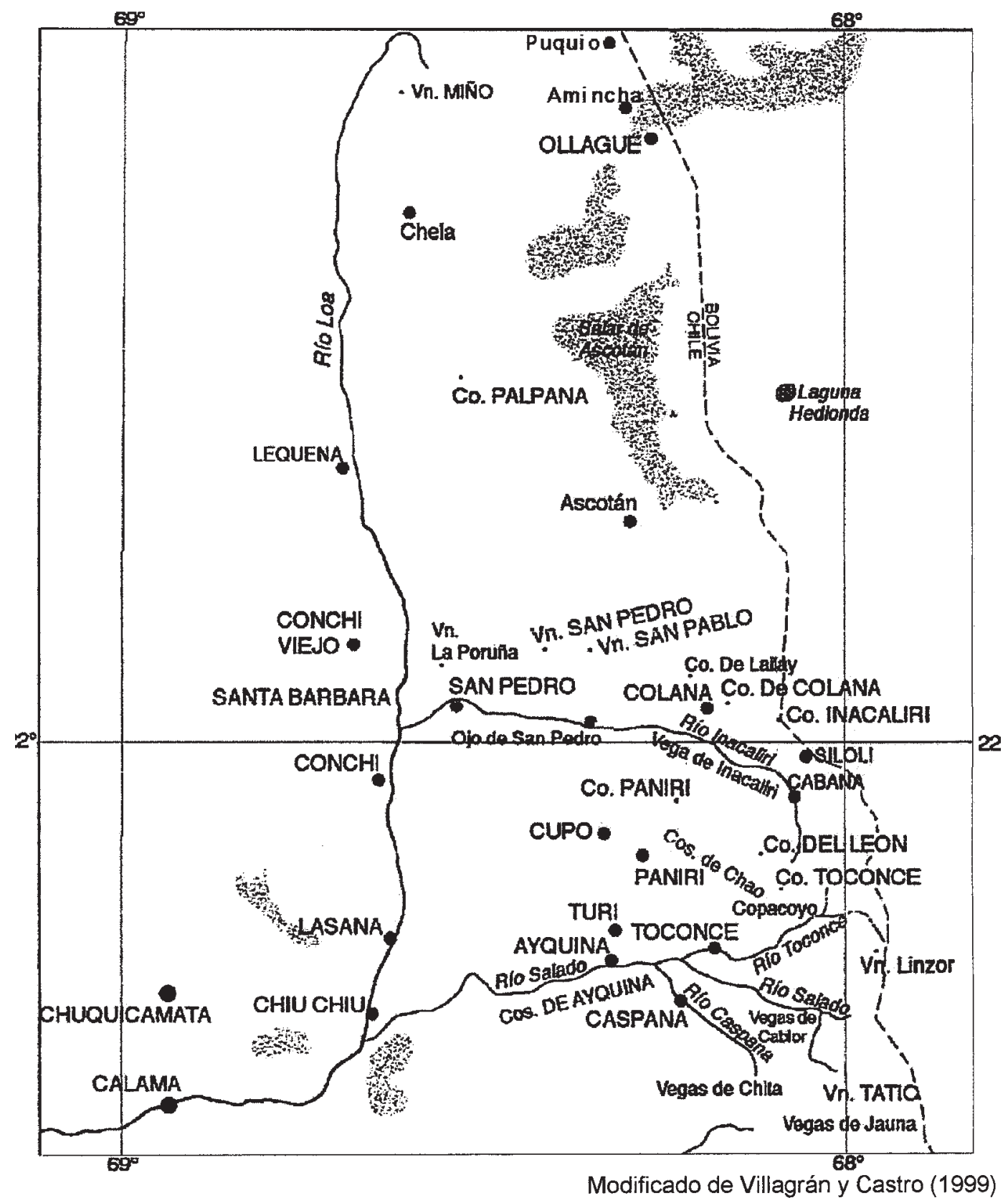

Figura 1: Ubicación de las unidades de estudios 


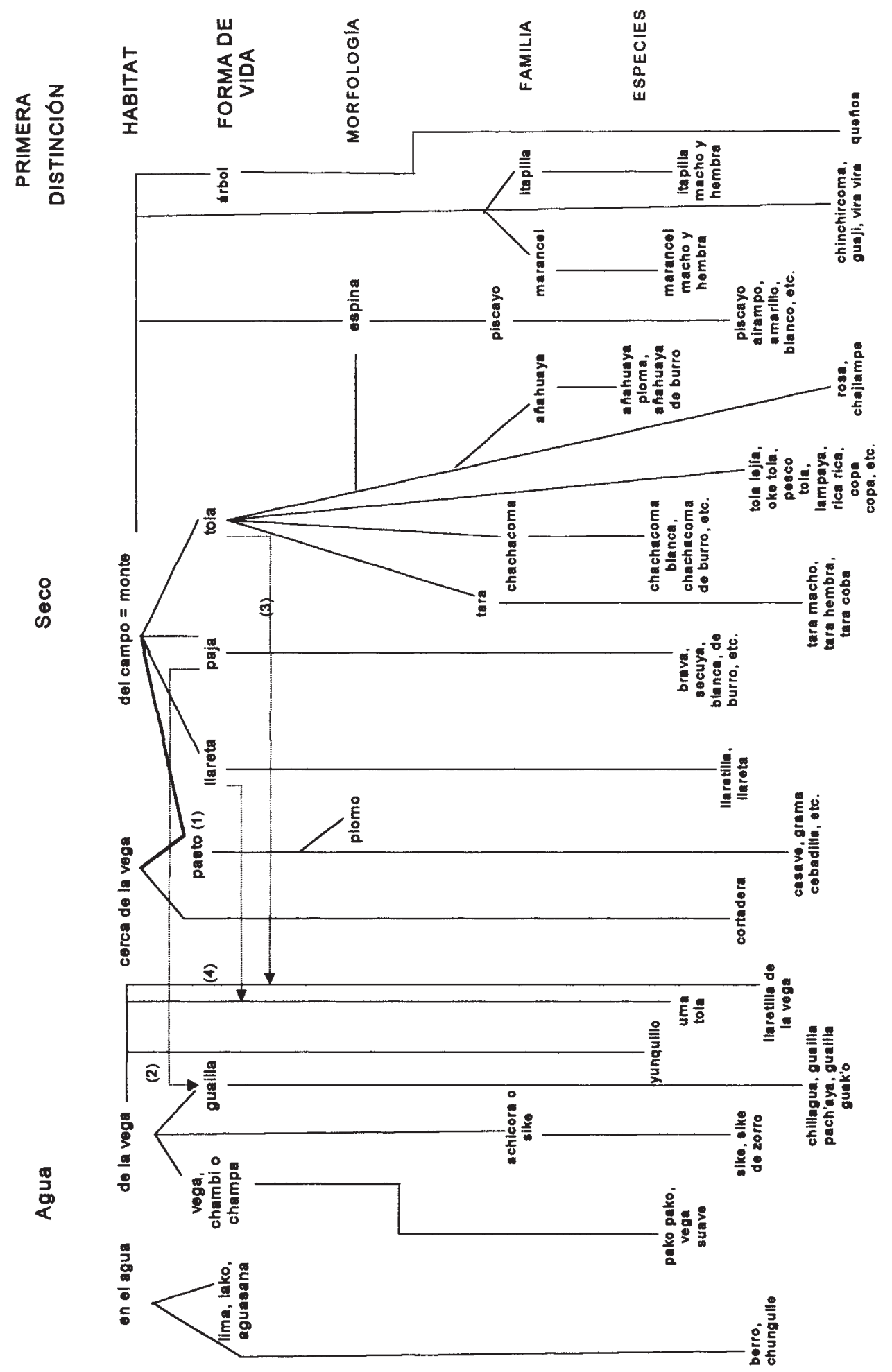

Figura 2: Clasificaciones de las plantas 

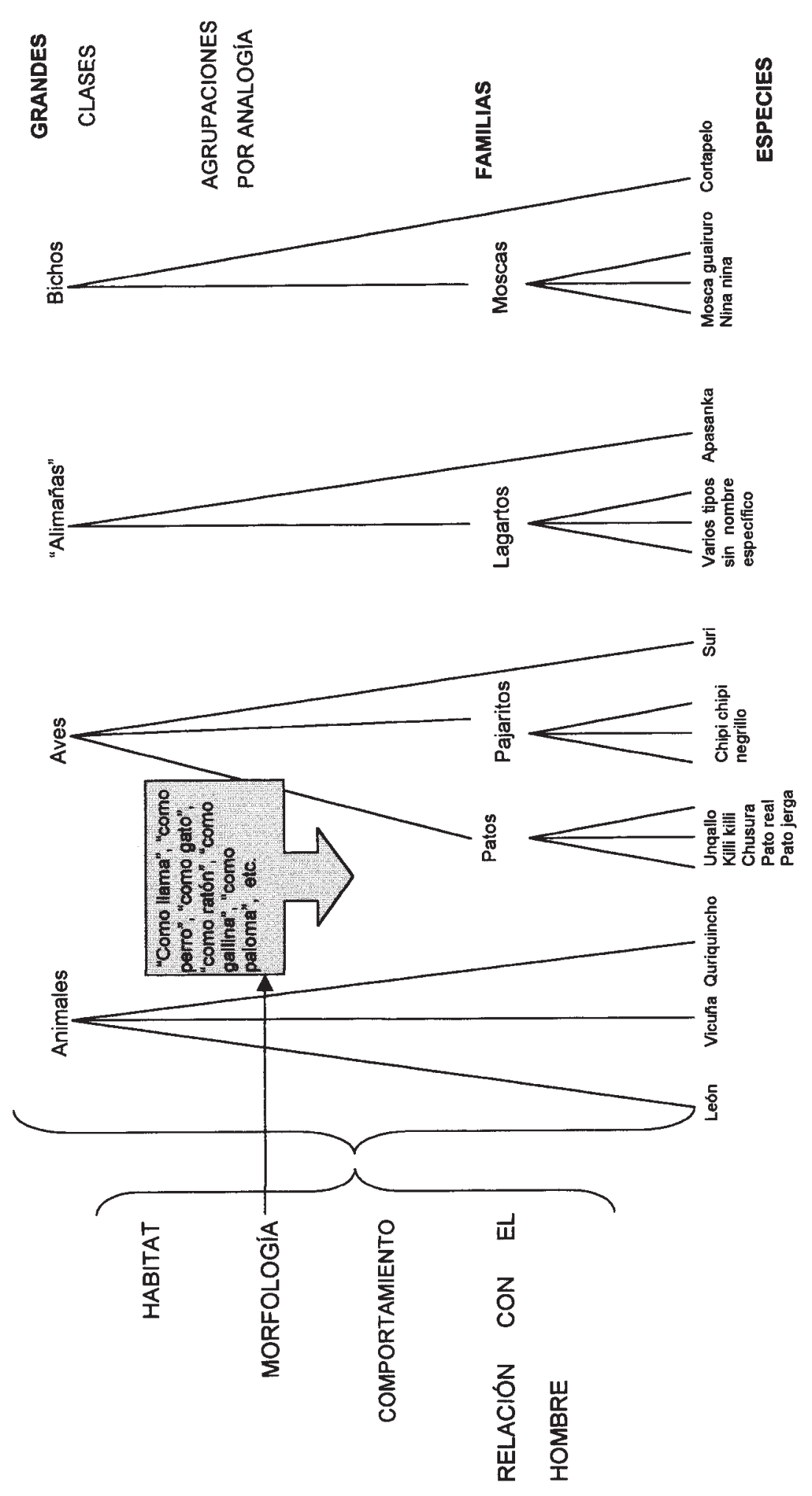

Figura 3: Esquema taxonómico de animales silvestres 


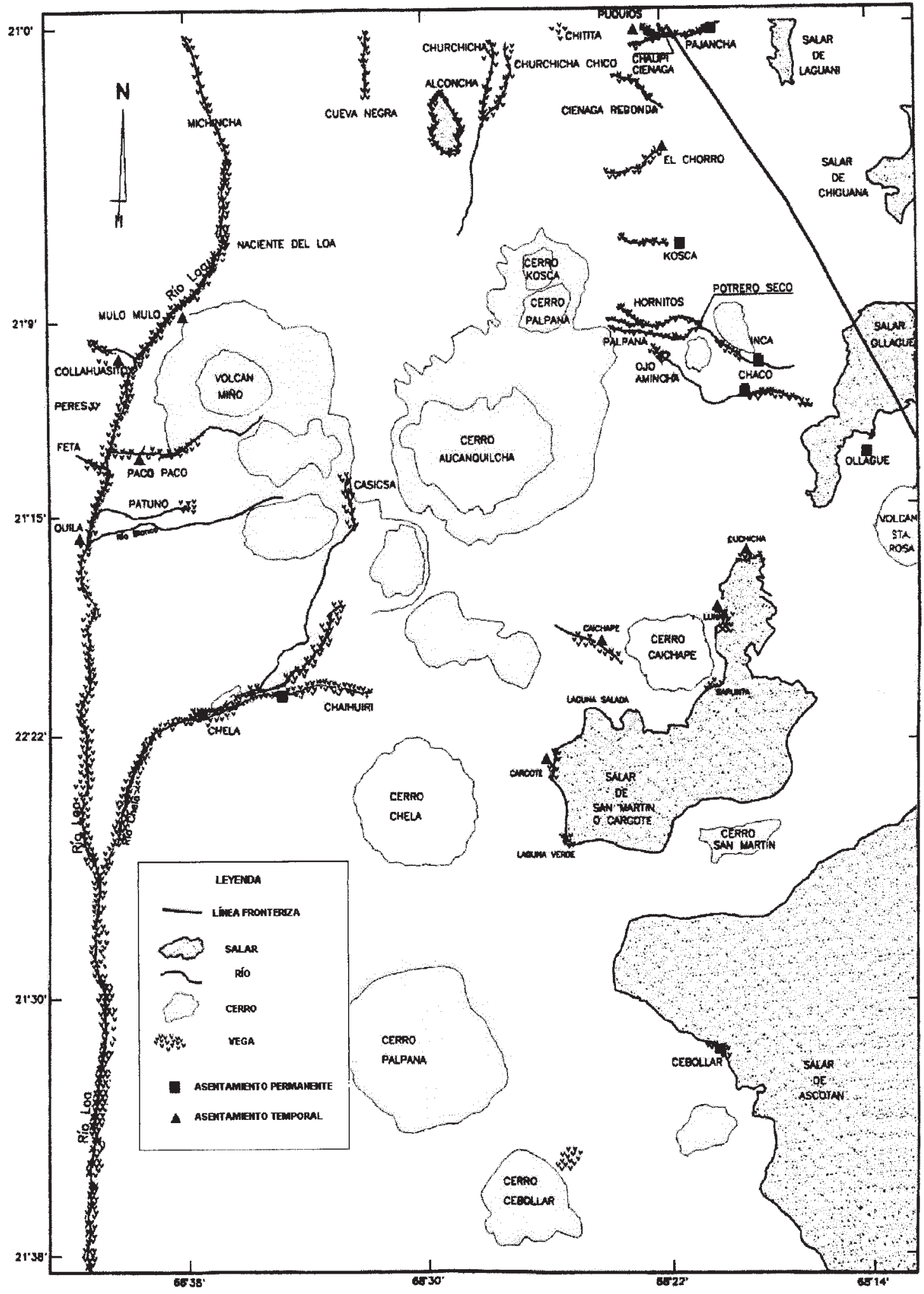

Figura 4: Vegas y asentamientos de pastores 